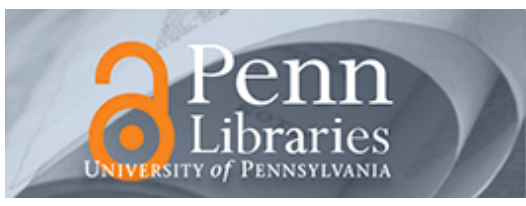

University of Pennsylvania ScholarlyCommons

1991

\title{
The Top-Down and Bottom-Up Systems of Musical Implication: Building on Meyer's Theory of Emotional Syntax
}

Eugene Narmour

University of Pennsylvania, enarmour@sas.upenn.edu

Follow this and additional works at: http://repository.upenn.edu/music_papers

Part of the Musicology Commons, and the Music Theory Commons

\section{Recommended Citation}

Narmour, E. (1991). The Top-Down and Bottom-Up Systems of Musical Implication: Building on Meyer's Theory of Emotional Syntax. Music Perception: An Interdisciplinary Journal, 9 (1), 1-26. http://dx.doi.org/10.2307/40286156 


\title{
The Top-Down and Bottom-Up Systems of Musical Implication: Building on Meyer's Theory of Emotional Syntax
}

\begin{abstract}
The implication-realization model hypothesizes that emotional syntax in music is a product of two expectation systems - one top down, the other bottom up. Syntactic mismatch or conflict in realizations can occur either within each system or between them. The theory argues that interruption or suppression of parametric expectations generated separately by the two systems explains certain types of recurrent aesthetic strategies in melodic composition and accounts for the most common kinds of musical forms (AAA, $\mathrm{AAB}$, $\mathrm{ABB}, \mathrm{ABC}$, and $\mathrm{ABA}$ ).
\end{abstract}

\section{Disciplines}

Music | Musicology | Music Theory 


\title{
The Top-Down and Bottom-Up Systems of Musical Implication: Building on Meyer's Theory of Emotional Syntax
}

\author{
EUGENE NARMOUR \\ University of Pennsylvania
}

\begin{abstract}
The implication-realization model hypothesizes that emotional syntax in music is a product of two expectation systems-one top down, the other bottom up. Syntactic mismatch or conflict in realizations can occur either within each system or between them. The theory argues that interruption or suppression of parametric expectations generated separately by the two systems explains certain types of recurrent aesthetic strategies in melodic composition and accounts for the most common kinds of musical forms ( $\mathrm{AAA}, \mathrm{AAB}, \mathrm{ABB}, \mathrm{ABC}$, and $\mathrm{ABA}$ ).
\end{abstract}

\section{Introduction}

It is widely accepted that affect and arousal stem from the interruption and/or release of psychological tendencies (Rosner, 1988). As Mandler (1964, 1984, pp. 15-48) admirably demonstrates, arguments for this view have a long and impressive history (Angier, 1927; Dewey, 1894, 1895; Hebb, 1946, 1949; Herbart, 1816/1891; Miller, Galanter, \& Pribram, 1960; Paulhan, 1887, 1930; Schachter \& Singer, 1962). There is, he insists (1984, p. 171), "no available evidence against the hypothesis that the interruption of highly organized activities generates autonomic arousal."

Yet, because the correlation between measure of arousal and felt emotion is low, arousal is apparently not a necessary condition for emotion (see Reisenzein, 1983; summarized in Frijda, 1986). Some emotions, for instance-particularly those resulting from syntactic noncongruencesmay be purely cognitive in origin and thus involve no physiological arousal. In these cases, the perceiver's appraisal of expectation forms a "cognitive background that holds relevant coding categories in readiness and upon which events impinge" (Frijda, 1986, p. 326). Even when emotional response appears outwardly as a state of active, relational, intentional, and controlled readiness (Frijda, 1986) vis-à-vis some particular

Requests for reprints may be sent to Eugene Narmour, 201 South 34th Street, Department of Music, University of Pennsylvania, Philadelphia, PA 19104. 
Allegro con brio
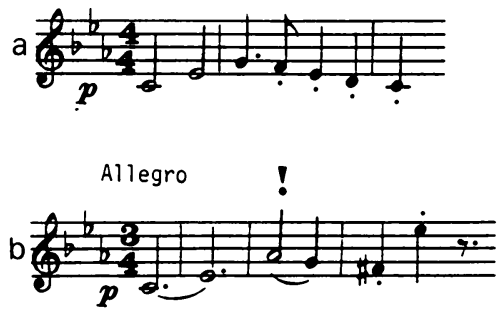

Fig. 1. (a) Beethoven, Piano Concerto No. 3, I, mm. 1-3; (b) Mozart, Piano Concerto No. 24, K. 491, I, mm. 1-4.

eliciting event, agent, or object (Ortony, Clore, \& Collins, 1988), cognition remains emotionally essential in interpreting expectation from realization.

Music theory largely conceives conflicting mismatches in syntactic signal as either interruptions or stylistic discrepancies involving learned expectations, owing to Leonard B. Meyer's pathbreaking book on musical emotion (1956; see also Meyer, 1973, 1976, and 1982). In Figure 1b, for instance, the syntactic affect (!) of the $\mathrm{Ab}$ in the $\mathrm{C}-\mathrm{Eb}-\mathrm{Ab}$ realization is partly dependent on its deviation from the more common stylistic schema of C-Eb-G, as shown in Figure 1a. ${ }^{1}$ Of course, the schematic expectancy that the melodic $\mathrm{C}-\mathrm{E} b$ stylistically evokes involves not just pitch but pitch in a highly common, parametric complex of relations. For frequency and utility in the cognitive invocation of schematic expectancy must correlate (Rumelhart \& Ortony, 1977).

Meyer himself (1973, p. 213) cogently summarizes the conflict/ mismatch view of musical affect: "the delight of intelligent mental play and the excitement of its complement, affective experience, are significantly dependent on the deviation of a particular musical event from the archetype or schema of which it is an instance." In musical cognition the importance of top-down schemata is, of course, well known and much discussed today (e.g., Bharucha, 1984; Butler, 1989; Dowling \& Harwood, 1986; Gjerdingen, 1988; Krumhansl, 1983, 1990; Lerdahl \& Jackendoff, 1983; Rosner \& Meyer, 1982, 1986).

Researchers in musical cognition, however, have also convincingly argued for the necessity of nonschematic, panstylistic rules (e.g., Deutsch \& Feroe, 1981; Deutsch, 1982; Francès, 1958, 1988; Serafine, 1988). It seems likely, therefore, that bottom-up processing systems of expectation also entail affective possibilities of conflict and interruption. These too, then, must contribute to musical affect.

1. Both examples are highly conformant in every parametric respect, so listeners could easily confuse the start of one piece with the start of another. 


\section{The Two Expectation Systems}

The implication-realization model expostulated here (Narmour, 1977, 1983, 1984, 1989a, 1989b, 1990, 1992, in press) hypothesizes simultaneous top-down and bottom-up input systems as theoretical constants. ${ }^{2}$ Following philosophical and psychological arguments made by Fodor (1983; for criticisms of Fodor, see Jackendoff, 1987, pp. 260-265), the model conceives such perceptual-cognitive systems as only partly interconnected and thus governed by rules that are ineliminably independent.

The top-down system is flexible, variable, and empirically driven. In it, listeners constructively match and compare representative schemata to current input. Schemata range from highly instantiated parametric complexes within a style (e.g., the contexted C-Ebs in Figure 1) to extremely generalized structurings of the elementary materials of a style (e.g., scalestep hierarchies in tonal music). Musically, this top-down system divides into intra- and extraopus style, where both prior learning before listening to a piece and immediate learning during a piece influence expectation.

In contrast, the bottom-up mode constitutes an automatic, unconscious, preprogrammed, "brute" system that operates on parametric primitives (e.g., intervals, registral directions, durations, perceptual consonances and dissonances). ${ }^{3}$ I will also argue that the bottom-up system processes formal similarity and formal difference. As Jackendoff (in press) vividly summarizes, the bottom-up system always attends to music as if it were encountering it for the very first time. Put another way, bottom-up perception is, in some fundamental sense, impervious to conscious will (see Bregman, 1990) and thus the invocation of previously learned, stylestructural obtrusion.

Given these general hypotheses - that two separate expectation systems interact yet remain independent-it follows that conflict, mismatch, and interruption can occur either within the bottom-up system; within the top-down system, or between the two systems themselves. I will discuss each of these in turn.

2. Terminologically, the words implication and realization are objective analytical glosses for subjective expectation and confirmation. Denial of realization is a similar gloss for the notion of interruption and/or conflict.

3. I say "perceptual consonances and dissonances" because top-down schematic learning also influences our harmonic cognitions of stability and instability. From the top down, for instance, listeners typically interpret harmonic sixths in early music toward the dissonant side of the ledger, whereas, from the bottom up, such sixths perceptually belong, I believe, to the realm of consonance. One other point: the category variables constituting parametric primitives rationalistically suggest various types of syntactic parametric scales by which one can measure degrees of implication, degrees of realization, degrees of denial (and thus surprise), and degrees of closure and nonclosure (see Narmour, 1990, chaps. 15-19). 


\section{The Basic Melodic Theory of the Bottom-Up System}

According to the implication-realization model, in the parameter of melody the bottom-up system generates implications (= expectations) affecting registral direction and intervallic motion. Realization (confirmation) of both, one, or none of these melodic dimensions may occur, with corresponding effects in the syntactic strength of the musical emotion present. ${ }^{4}$

Two specific hypotheses in the model underlie the bottom-up system. The first is that of continuation. It says, all other top-down stylistic and parametric things being equal, that small intervals imply a continuation of registral direction and a continuation of intervallic similarity. It also says that realizations of these patterns function nonclosurally. Psychologically, this hypothesis of continuation rests on the bottom-up Gestalt laws of similarity, proximity, and common fate or common direction (Pomerantz, 1981). Such laws govern the organization of processes and iterations in melodic patterns. ${ }^{5}$

In terms of subconscious expectation, I symbolize this hypothesis of continuation in the following way: if $a+a$ in registral direction or intervallic motion occurs, then listeners expect another a (see Figure 2, where the arrow means "implies," signifying nonclosure; the small letters refer to the proximity between individual tones). 6

The second hypothesis, that of reversal, says, ceteris paribus, that large intervals imply a change in registral direction (up/down, down/up, up/ lateral, or down/lateral) and a differentiated change in intervallic motion from large to small. 7 In terms of function, realization of reversal creates closure (whether articulative, and thus remaining wholly on the level of its occurrence; or formational, and thus portending a higher level but not reaching it; or transformational and thus actually creating a new hierarchical level). Implication and realization of reversal thus stand theoretically opposite the registral and intervallic functional properties of continuation (i.e., opposite the unclosed $\mathrm{a}+\mathrm{a}+\mathrm{a}$ realizations of process).

We may symbolize the hypothesis of reversal in the following way: if $a+b$ in pitch occurs, then listeners expect $c$ in terms of registral direction

4. Durational, harmonic, and metric patternings may, however, strengthen, weaken, or even suppress completely implications generated from the bottom up.

5. I use the word "process" here to refer to specific parametric patterns of registral and intervallic motion, not to complex combinations of many parameters.

6. As Figure 2 shows, melodic implication is also place-specific (in terms of metric level) and duration-specific (two quarter notes imply a tone of another duration at least at the quarter-note level).

7. As with "process," I use the word "reversal" to refer to parametric relations in melody alone (registral direction and intervallic motion) rather than to complex parametric combinations. 


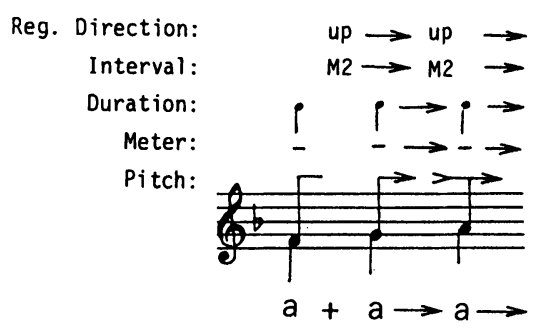

Fig. 2.

and intervallic motion (see Figure 3, where the tail catching the arrow of implication signifies realization and closure). ${ }^{8}$

Since psychology only preliminarily grounds the concept of reversal, reversal basically occupies the status of a symmetrical construct in the theory (for the psychological evidence supporting the implicative concepts of melodic reversal and melodic continuation in the model, see Krumhansl, in press; also reported in Krumhansl \& Schellenberg, 1990). ${ }^{9}$

\section{Conflict within the Bottom-Up System}

From these two hypotheses, one is led to posit complete or partial denials of implied realization. Thus, theoretically, in terms of the bottom-up input system in melody, interruption of either registral direction or intervallic motion or both will entail some degree of surprise. ${ }^{10}$ For instance, in Figure 4, both a typical escape-tone pattern (F-G-E, up/ down) and a somewhat "distant" neighboring-tone pattern (C-A-C, down/ up) create a mildly satisfying aesthetic configuration. Both patterns do so because, according to the theory, they realize the expected intervallic similarity (A + A, small interval to small interval, arrow to tail) while denying the implied registral direction (symbolized by the slash following the arrow: i.e., the up/down or down/up of the $\mathrm{A}+\mathrm{Bs}$ in Figure 4 should, according to the theory, have continued in similar registral fashion as $\mathrm{A}+\mathrm{A}$, as up/up or down/down). Note here symbologically that capital letters refer to registral and intervallic relations between any pair of ad-

8. Note that what in retrospect looks like $a+b+b$ in terms of pitch pairs is really in prospect $a+b+c$ in terms of the overall relation among all three notes. That is, each pair of tones makes an interval, and it is the emergent property of intervallic relations that determine similarity $(A+A)$ and difference $(A+B)$ - and thus the ascription of letters to individual pitches.

9. Process and reversal form two of the basic melodic archetypes of the theory. For the whole theory, the interested reader should consult Narmour $(1990,1992)$.

10. Of course, by the word "surprise" I do not refer here to global events that shock but rather to tiny jolts that mildly (and pleasantly) alter the operations of our neuronal pathways. In its mode of criticism, music theory is a science concerned with extreme psychological subtlety. 


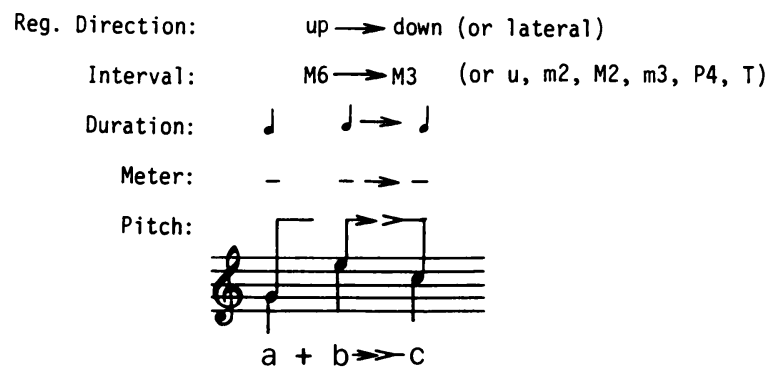

Fig. 3
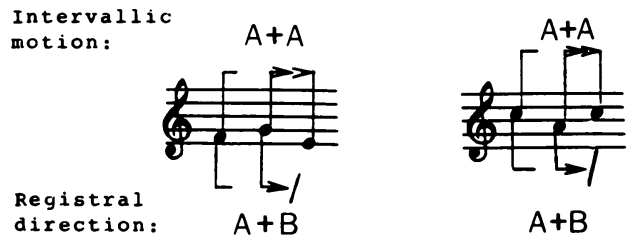

Fig. 4

jacent pitches. And observe that, although any two pitches establish a registral direction, intervallic motion entails a relation among three adjacent pitches.

Likewise, given the same beginning from a small interval, an ascending pattern that unexpectedly leaps creates an agreeable syntactic effect. The reason is that, although the ensuing leap realizes the expected registral continuation $(\mathrm{A}+\mathrm{A})$, it denies the implied intervallic motion of small interval to small interval (i.e., differentiation from small interval to large interval $[A+B]$ replaces the implied intervallic similarity; see Figure 5). Of course, denial (=interruption) of both implied intervallic motion and registral direction initiated from a small interval also occurs, as Figure 6 illustrates. Note here in measure 2 the denial of the implied, similar intervallic motion (in the context of $\mathrm{D}$ major) but not the denial of registral direction (up is followed by up). In terms of the theory of the bottom-up system, large initial intervals admit the same kinds of intervallic and registral interruptions (see Figure 7$).{ }^{11}$

11. Indeed, by taking into account the intervallic and registral variables, one discovers eight different kinds of structures that will parse almost all melodic patterns to be found (I say "almost" because three other archetypal structures must be added to this list: registral return, dyad, and monad). Elsewhere, I have given these structures names and analytical symbols according to their prospective and retrospective nature (see Narmour, 1990, 1992). A schema theorist might ask why such archetypal structures are not themselves simply highly abstraft schemata (generic mental structures) rather than products of a bottom-up, input processing system. Space does not permit me to go into this discussion here, but the interested reader should see part 1 of Narmour (1990). For the general psychological arguments why the world of cognition and perception cannot be reduced to schemata, the reader should consult Fodor (1983). 


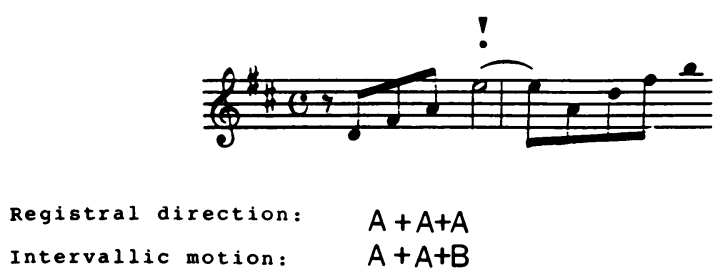

Fig. 5. Handel, Sonata for Violin and Continuo, I (Affettuoso), HWV 371, mm. 1-2.

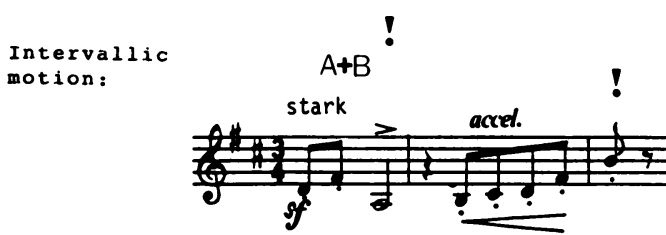

Registral

direction:

$A+B$

Fig. 6. Mahler, Symphony No. 5, III (Kräftig, nicht zu schnell), mm. 1-2.

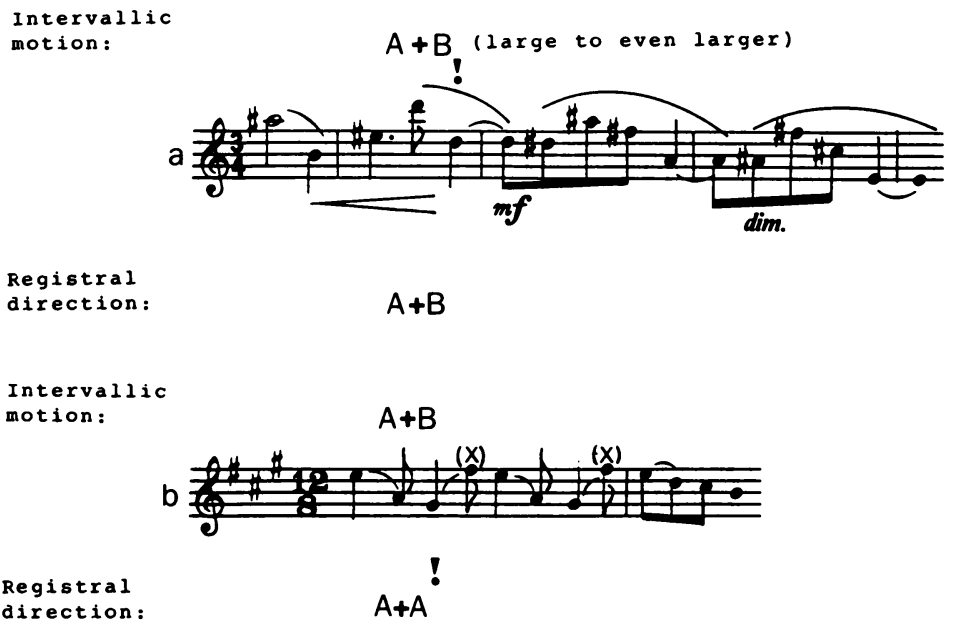

Fig. 7. (a) Bartók, First String Quartet, II (Allegretto), mm. 50-53; (b) Handel, Sonata for Violin and Continuo, IV (Allegro), HWV 361, m. 1.

Such partial realizations of hypothesized registral direction and intervallic motion, incidentally, should not be confused with the dimension of pitch alone, the surprise of which depends in part on a top-down awareness of mode. Figure 8, for instance, begins similarly to Figure 1 and thus belongs somewhat to the same schema-a schema in which an initial minor third (the C-Eb) in this style, this register, this timbre, this texture, and so forth invariably evokes degrees $\hat{1}-\hat{3}$ of the minor mode (as opposed to, say, degrees $\hat{3}-\hat{5}, \hat{2}-\hat{4}$, or $\hat{7}-\hat{2}$ of the major mode). But the $F \#$ in this figure is a surprise in terms of pitch although not in terms of either registral 


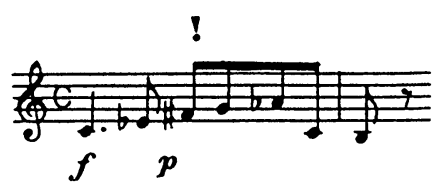

Fig. 8. Mozart, Fantasy (Adagio), K. 396, m. 1.

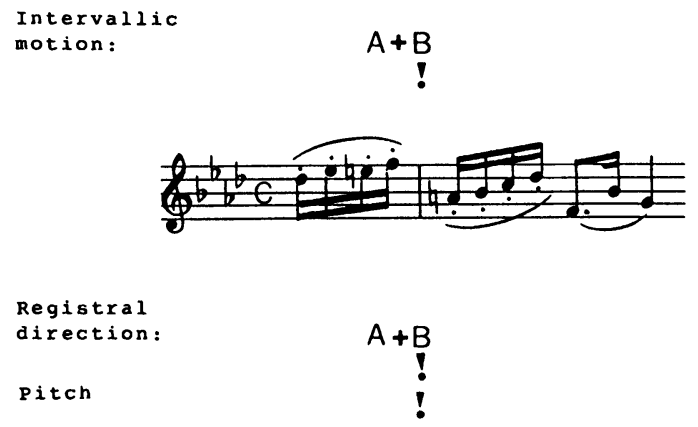

Fig. 9. Schumann, Symphony No. 3, III (Nicht schnell), mm. 10-11.

direction (which continues the ascent) or intervallic motion (the two minor thirds are identical).

Naturally, one can also find examples that deny implied registral direction, intervallic motion, and expected mode (see Figure 9, where the abrupt, differentiated downward leap to the transitory A 4 denies registral ascent, and intervallic similarity, momentarily contradicting the previously established key of $\mathrm{Ab}$ major as well).

\section{Basic Bottom-Up Strategies in an Aesthetic Syntax of Melody}

The norms of continuation and reversal and the affective potential of their partial or complete realizations enable one to conjecture rules governing some of the more common aesthetic strategies in melodic composition. These in turn allow one cognitively to understand why in all styles certain kinds of melodic configurations persist. For instance, if the rule of continuation, which says that $a+a$ implies $a$, is true, then it follows that a pitch configuration like $a+a+b$ will constitute an aesthetically effective compositional strategy. ${ }^{12}$ This explains the affect that we asso-

12. Observe that by " $a+a+b$ " I am not just discussing simple contrast but rather denial $(b)$ of an expected continuation $(a+a)$. It is the denial of implication that causes the syntactic conflict, not just change itself. 


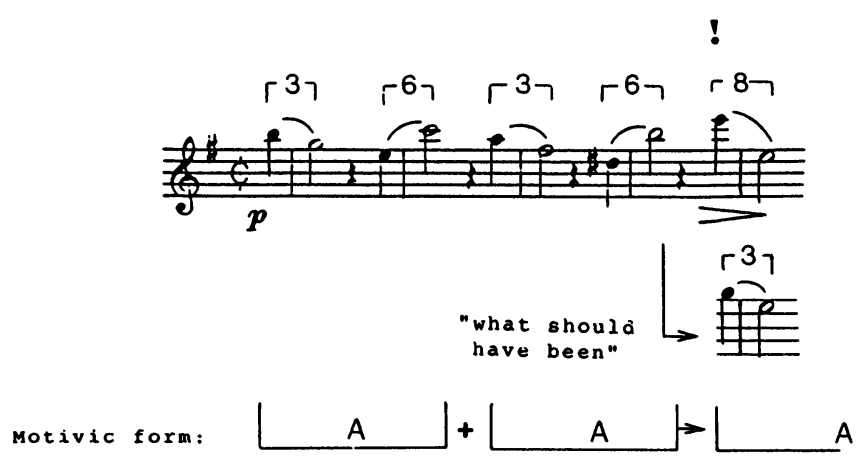

Fig. 10. Brahms, Symphony No. 4, I (Allegro non troppo), mm. 1-4.

ciate with deviations like those seen in Figures 4-6. It also explains why denial or variation of repetition is such a common procedure: change alters the expected sameness (see Figure 10, where sequential repetition causes the listener melodically to expect the pitch B in m. 4 to be followed by a descent to $G$ rather than by a continuation to a high $\mathrm{E}$; observe, however, that the half-note $\mathrm{E}$ in $\mathrm{m} .5$ partially restores the projected expectation).

Likewise, if the rule of reversal, which says that $\mathrm{a}+\mathrm{b}$ implies $\mathrm{c}$, is true, then logic dictates that the listener will also perceive a melodic configuration of $a+b+b+b$ as aesthetically effective. This explains the value composers attach to gap-filling (Meyer, 1973) and interval-filling (Schenker, 1956) melodies, where a series of similar steps $(b+b+b)$ retrospectively follow a prospectively differentiated leap $(a+b$; see Figure 11; for the psychological evidence supporting gap filling, see Rosner $\&$ Meyer, $1982,1986)$. Of course, in such melodic realizations the continued filling in eventually becomes predictable and thus, after a certain point, yields no more surprise, allowing the perceptual-cognitive system time to recover from the expected $a+b+c$, as it were. ${ }^{13}$

Theorists (e.g., Toch, 1977) and psychologists (e.g., Dowling \& Harwood, 1986) have long recognized that steps frequently succeed leaps $(a+b+b+b)$. And, as we see, it is also true that leaps frequently follow steps $(a+a+a+b$; again see Toch, 1977). The common occurrences of similar intervals preceding or following differentiated ones thus make for aesthetically effective compositional strategies-ones where parametric realizations go against implications generated within the bottom-up system.

13. Note that, discontiguously, the end of each pattern forms a near registral return $\left(a^{\prime}\right)$ with the beginning tone. 


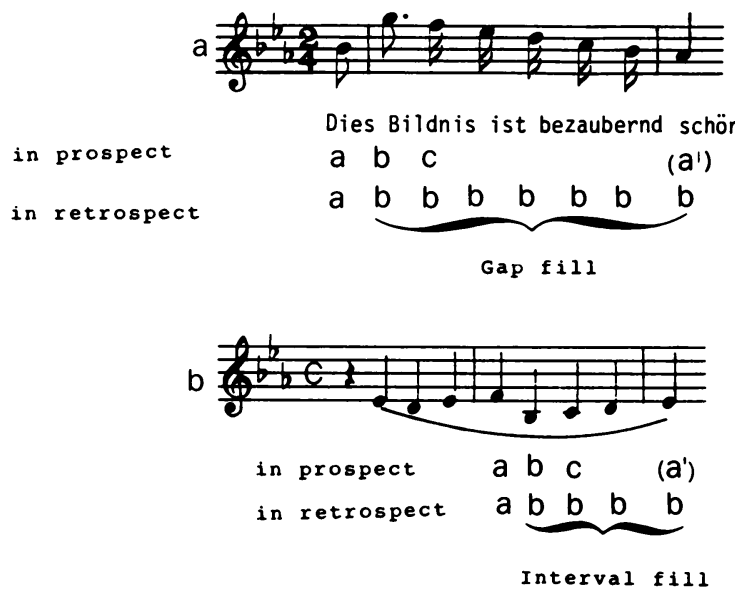

Fig. 11. (a) Mozart, The Magic Flute, Aria No. 3 (Larghetto); (b) Bach, Fugue for Lute, BWV 998.

\section{Basic Bottom-Up Strategies in an Aesthetic Syntax of Form: Why Bar Forms and Echo Forms Occur, and Why Listeners Expect Them}

Musical forms also exhibit these basic aesthetic plans, where differentiation both follows and precedes similarity - that is, where a realized $\mathrm{A}+\mathrm{A}+\mathrm{B}$ displaces an implied $\mathrm{A}+\mathrm{A}+\mathrm{A}$, and where a realized $A+B+B$ substitutes for an implied A + B + C. In both cases, such formal denial ensures cognitive interest (and therefore the possibility of an aesthetic experience) since both redundant repetition $(\mathrm{A}+\mathrm{A}+\mathrm{A} \ldots)$ and incessant differentiation $(A+B+C \ldots$ ) rapidly recede to ground. It is not by accident, for instance, that exercises found in performing manuals overuse repetitive sequences because the resultant reduction of intrinsic musical interest allows the practicing musician to concentrate on perfecting technique.

In short, the bottom-up compositional strategies discussed earlier with reference to implied intervallic motion and implied registral direction in melody also apply to the phenomenon of form on all hierarchical levels. Significantly, this means that the aesthetic effect of form partly originates in the bottom-up system. One typically finds, for instance, differentiating formal change $(A+A+B)$ breaking off melodic-harmonic sequences, where $A+A$ implies another $A$ (see Figure 12a). Likewise, bar-forms $(\mathrm{A}+\mathrm{A}+\mathrm{B})$, legion in all styles and recognized throughout music history, aesthetically terminate the bottom-up system's forms of $\mathrm{A}+\mathrm{A}$ implying A (see Figure $12 \mathrm{~b}) .{ }^{14}$

14. Note that Figure 15a illustrates bar forms on two different levels. 


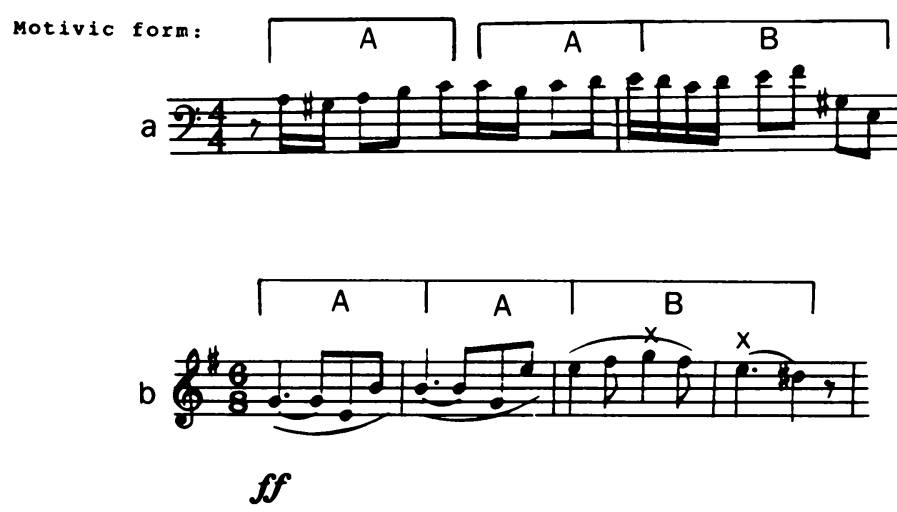

Fig. 12. (a) Bach, Fugue 20, Well-Tempered Clavier I, mm. 1-2; (b) Beethoven, Sonata, op. 109, II (Prestissimo), mm. 1-4.

Equally common as an aesthetic interruption is the form of $\mathrm{A}+\mathrm{B}+\mathrm{B}$ (echo and near echo), such as that in Figure 13. Here, in terms of the bottom-up, brute system, the initial form of $\mathrm{A}+\mathrm{B}$ implies continuing differentiation $(C)$. What one gets instead is a surprising, echoing repetition (B). ${ }^{15}$

Such ABB forms occur frequently in late opera-seria arias and in early classic symphonies written between 1750 and 1770 (see Weimer, 1984). Contemporaneous theorists recognized them as well. The eighteenthcentury theorist Heinrich Christoph Koch (1781-1793/1983, pp. 45-48), for instance, describes such repetitions as melodic "appendices," claiming that they emphasize the meaning of the phrase.

Figure 14 summarizes the theoretical argument concerning the bottom-up generation of formal expectancy and the concomitant emergence of aesthetic strategies in melodic composition.

\section{Formal Conflict between the Two Systems: Suppression}

That the bottom-up system generates formal implications of similarity (A) from $\mathrm{A}+\mathrm{A}$ and implications of differentiation (C) from $\mathrm{A}+\mathrm{B}$ also explains why the forms $A+A+B$ and $A+B+B$ are so aesthetically long-lived: they create interruption, mismatch, and conflict within the bottom-up system.

But they can also produce conflict between the bottom-up and the top-down systems. For so common are such formal deviations that, cog-

15. Of course, not all AABs (bar forms) or ABBs (echo forms) are alike. Some involve deep hierarchical embedding; others are relatively shallow. Presumably, whichever occurs will have a profound effect on how listeners interpret the aesthetic effect of the form. 


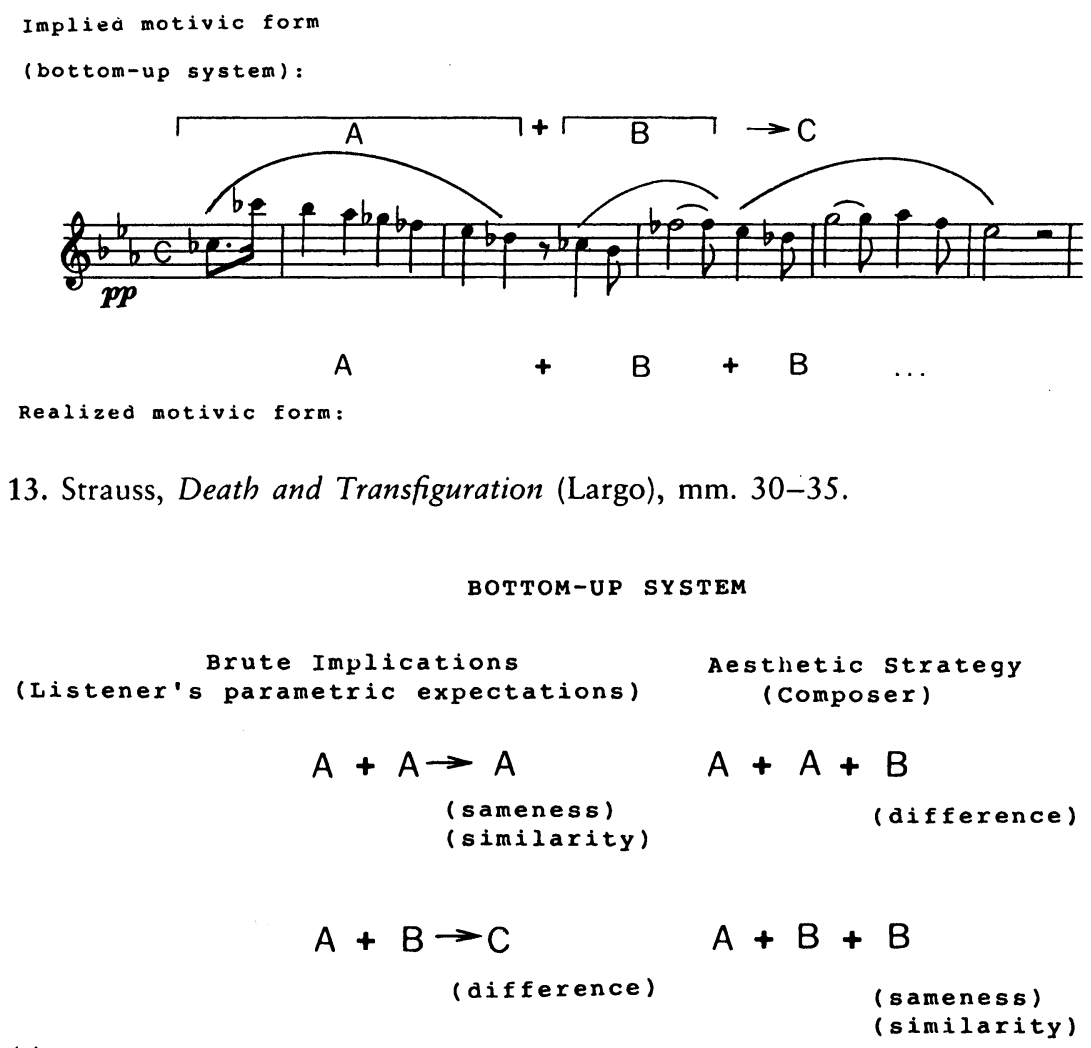

Fig. 14.

nitively, they can come to function as learned generic schemata. ${ }^{16}$ That is, from the top down, experienced listeners would, over time, learn to project differentiation (B) from an initial $A+A$ form (as in the analysis above the music in Figure 15a; note in measures 3-4 how the form appears on two different levels $[\mathrm{AAB}=\mathrm{BBC}])$. Likewise, experienced listeners would also learn to project formal similarity ( $B$ or $B^{\prime}$ ) from an initial $A+B$ (as in Figure 15b).

Observe in measure 3 of Figure $15 \mathrm{a}$, however, that the $\mathrm{A}+\mathrm{A}$ on the beat level also formally functions as $B+B$ in conjunction with the $A$ at the bar level in measure 2 (shown underneath the music). Neatly dovetailing $\mathrm{ABB}$ with $\mathrm{BBC}$ - and zigzagging hierarchically from a higher to a lower and back up to a higher level - the overall formal configuration of

16. Schemata exist on all levels, from highly abstract, generic categories, relational families, and prototypes (e.g., the known forms of music) to more concrete configurations (e.g., common tonal schemes, as in Schenker's various Brechungen structuring the Ursatz), to highly specific instantiations. It seems unlikely to me, however, that listeners track more than three (or possibly four) levels of formal expectations at a time (depending on the inherent parametric complexity). 


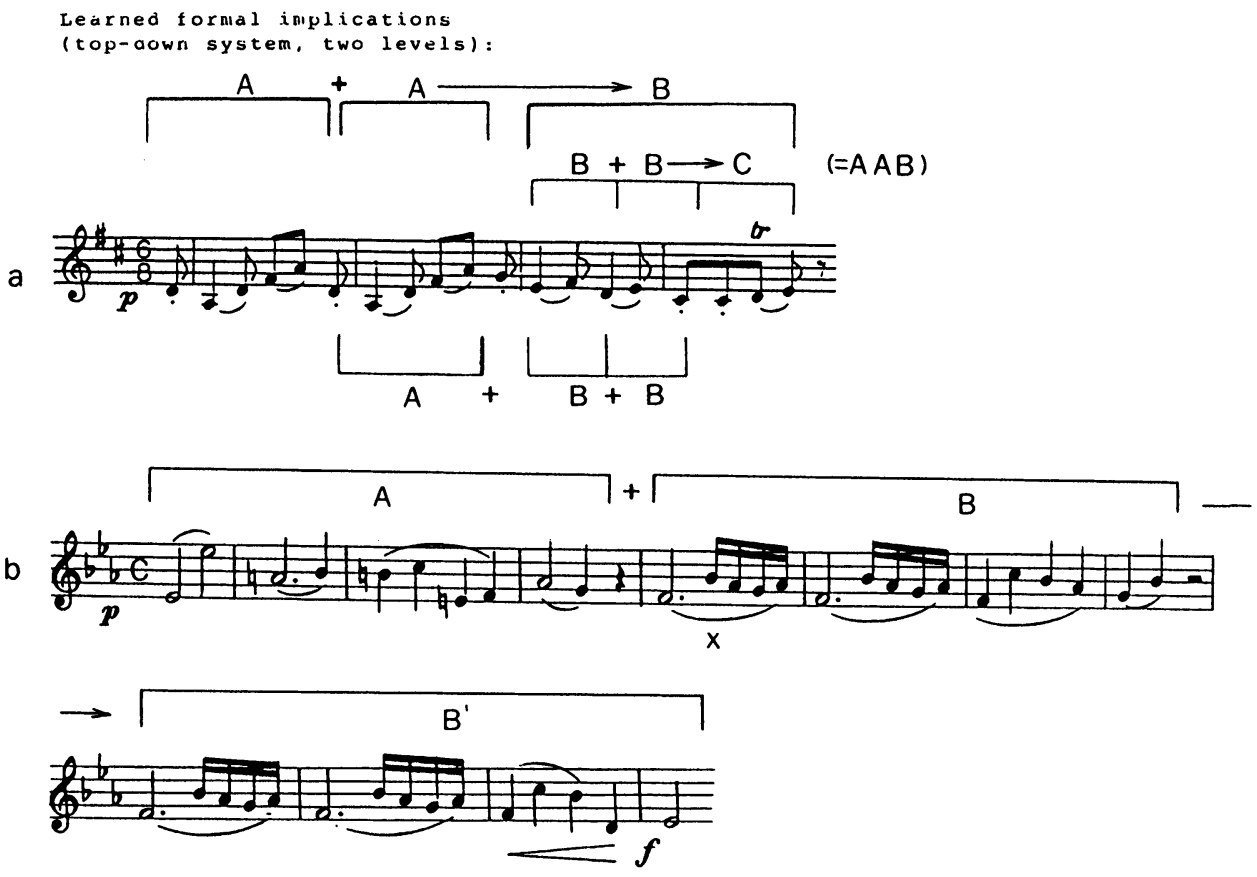

Fig. 15. (a) Beethoven, Violin Concerto, III (Rondo), mm. 1-4 (Allegro); (b) Mozart, Quartet, K. 428, I (Allegro non troppo), mm. 1-4.

$\mathrm{ABBC}$ of course would also easily lend itself to stylistic learning, such that sophisticated listeners would formally project from an initial A + A not only a B at a higher level but also a B composed of BBC on a lower level.

In terms of the bottom-up system, the theory thus cognitively and economically explains why hierarchies in so many classical melodies have formal shapes like that of Figure $15 \mathrm{a}: \mathrm{AAB}$ and $\mathrm{BBC}$ deny the expected bottom-up repetition $(A+A \rightarrow A)$, while $A B B$ denies the expected bottom-up differentiation $(A+B \rightarrow C)$.

Furthermore, the theory explains why so many $\mathrm{A}+\mathrm{A}+\mathrm{B}$ forms start off as if they were going to replicate $A+A+A$. For once listeners stylistically learn from the top down to expect B from A + A (instead of A), it makes aesthetic sense in terms of compositional strategy for a composer to "play" to the bottom-up system, keeping the listener's "cognizing" off balance, if only for a moment. At the very start of measure 4 in Figure $15 \mathrm{a}$, for instance, it momentarily appears as if $\mathrm{C} \#$ will continue the sequence established in measure 3 (E-F\#-D-E-C\# ... D-B). Such formal configurations - we might symbolize this "trying to have it both ways" as $\mathrm{A}+\mathrm{A}+\mathrm{AB}-$ are found everywhere in melody.

In short, the conflicting noncongruence between the twin-tracking implications and realizations of both the bottom-up and top-down systems 
enables one to understand the aesthetic value of interruptive strategies in various musical forms. Figure 16, conceptually obverse to Figure 14, illustrates the basic idea.

Observe that while it may appear contradictory to say that $\mathrm{A}+\mathrm{A}$ implies both A (bottom up, innate) and B (top down, learned), such possibilities cause no ongoing perceptual-cognitive ambiguity to the listener. For the top-down, learned system suppresses the bottom-up, innate system. But of course such suppression is not complete because both psychological systems are always independently operative. ${ }^{17}$ For both cognitive stylistic mapping (top down) and perceptual processing (bottom up) are necessary to cope with, understand, and assimilate novel events. ${ }^{18}$ Aesthetically, when implications between top-down and bottom-up systems conflict, the top-down system simply reduces the disruptive effect and thus the degree of surprise.

Figure 17 sums up the reciprocal symmetry between the two systems (a horizontal dashed line separates the two systems; crossing arrows show how the two systems generate the same form, although in different columns; note that formal implications in the top-down system are learned, whereas those in the bottom-up system are, in terms of the theory, innate). ${ }^{19}$

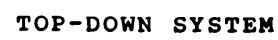

Learned Implications

(Listener's stylistic expectations)

Aesthetic strategy

(Composer)

$\begin{aligned} A+B & \rightarrow B \\ & (\text { sameness }) \\ & (\text { similarity })\end{aligned}$

$A+A \rightarrow B$

(difference)
$A+B+C$

(difference)

$A+A+A$

(sameness)

(similarity)

Fig. 16.

17. This differs from what some psychologists argue (e.g., Navon, 1977).

18. By itself, the top-down system is, of course, not only fallible but also inefficient in dealing with novel stimuli and unpredictable contexts.

19. Carried within this dual system is an explanation for style change based on both top-down learning and bottom-up perception and cognition. 


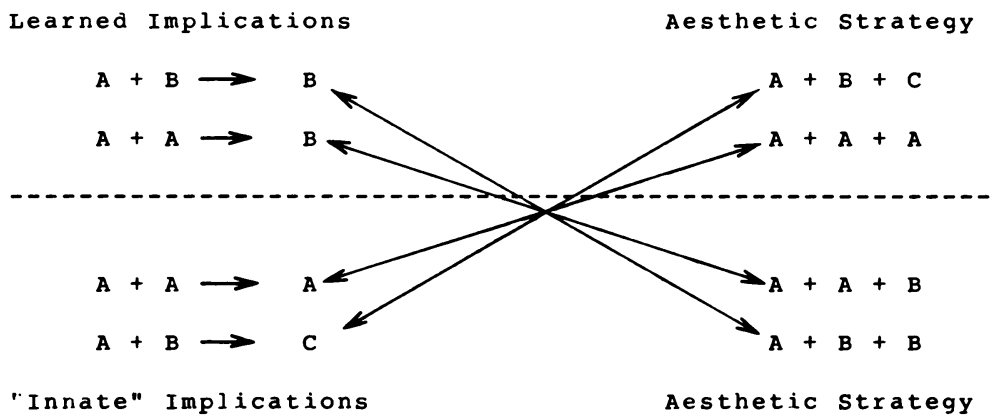

BOTTOM-UP SYSTEM

Fig. 17.

\section{The Problem of Falsifiability}

Although the preceding formulation presents no cognitive difficulty for the listener (owing to top-down's suppression of bottom up), it does seem to create a problem for the theory itself. For what would constitute a falsifiable demonstration? That is $\mathrm{AAA}, \mathrm{ABC}, \mathrm{AAB}$, and $\mathrm{ABB}$ seem formally to account for almost everything (except for formal return [ABA], to be discussed). But we know from the history of science that any time a theory appears to explain too much, a demonstrable procedure of falsifiability becomes epistemologically necessary.

As we recognize that $\mathrm{AAA}$ (continuation, repetition), $\mathrm{AAB}$ (bar from, differentiation, digression), and $\mathrm{ABB}$ (echo) represent some of the most common kinds of musical forms, the problem of music theory, therefore, is to explain why certain kinds of forms seem to correlate with certain kinds of parametric contexts. Both diachronically and synchronically, such correspondence must depend on some profound historicopsychological interrelation between the various aesthetic parametric configurations and the types of possible musical forms that exist. For certain kinds of parametric structurings must make certain kinds of syntactic formal arrangements aesthetically implausible and thus cognitively scarce. Currently, however, the field of music theory has only very vague notions about what such interrelations might look like and what theoretical principles might psychologically govern them.

That being said, it should nevertheless be psychologically feasible to test the formal claims of the model in connection with perceived aesthetic effect in melodic syntax. If in a previously established melody, for instance, we knew, on average, how both experienced and naive listeners rated the 
surprise of, say, a descending leap interrupting an ascending stepwise pattern, then, for the experimental trials, we could position the interrupting leap to terminate both contexts of formal repetition (... AA) and formal differentiation (... AB). According to the predictions of the theory, $\mathrm{A}+\mathrm{A}$ forms of similarity are supposed to enhance stylistic conditioning and thus facilitate expectation, so we could then see if repetition did indeed diminish the aesthetic effect of the surprising leap. The hypothesis is that manipulating the size of the leap, the direction of the leap, the scale step of the terminating tone, the character of the situational antecedents, the number of repetitions preceding the leap, their internal composition (simple versus complex), the amount and degree of formal differentiation, and so forth would produce monotonic results.

In any case, before assenting completely to the perceptual theory of aesthetic formal syntax outlined herein, one must await psychological evidence and theoretical arguments that produce a demonstrable logic of falsifiability.

\section{Top-Down Suppression of Parametric Implication}

But to return to the main discussion: to understand the parametric effects of suppression, consider top-down influence in the first three highly instantiated schemes of Figure $18 \mathrm{a}-\mathrm{c}$. Here, near registral return between individual pitches discontiguously connects the first and third or fourth tones of each case (E-F in Figure $18 \mathrm{a}, \mathrm{C}-\mathrm{Db}$ in $18 \mathrm{~b}, \mathrm{~A}-\mathrm{B} b$ in $18 \mathrm{c}$ ) such that the connecting influence of scale steps $\hat{S}$ to $\hat{\sigma}$ in the minor mode suppresses the continuing implication of the contiguous ascending intervals (C-F in Figure 18a, Ab-Db in 18b, F-Bb in 18c). ${ }^{20}$ Moreover, from the top-down learned system, the first three notes of these melodies conform to a known schema, a recognized style structure of zigzagging, down/up motion - whereby the near registral return discontiguously joins the initial and terminal tones of scale steps $\hat{5}$ to $\hat{\sigma}$ in the minor mode, causing the experienced listener not only to expect a change in registral direction but also a downward leap (see arguments in Narmour, 1990). At the same time, however, the aesthetic effect of this pattern and its continuing use throughout different musical styles partly depend on the bottom-up system, where registral and intervallic implications are denied.

To repeat: the conflicting noncongruence between bottom-up and topdown systems explains the aesthetic syntax and the emotional potential of certain kinds of interruptive strategies in musical composition. Note,

20. Scale steps, in my view, are "atomic schemata" (to use Rumelhart \& Ortony's term [1977]). See the discussion in Narmour (1990). Meyer (1989) also discusses the schematic nature of such examples. 

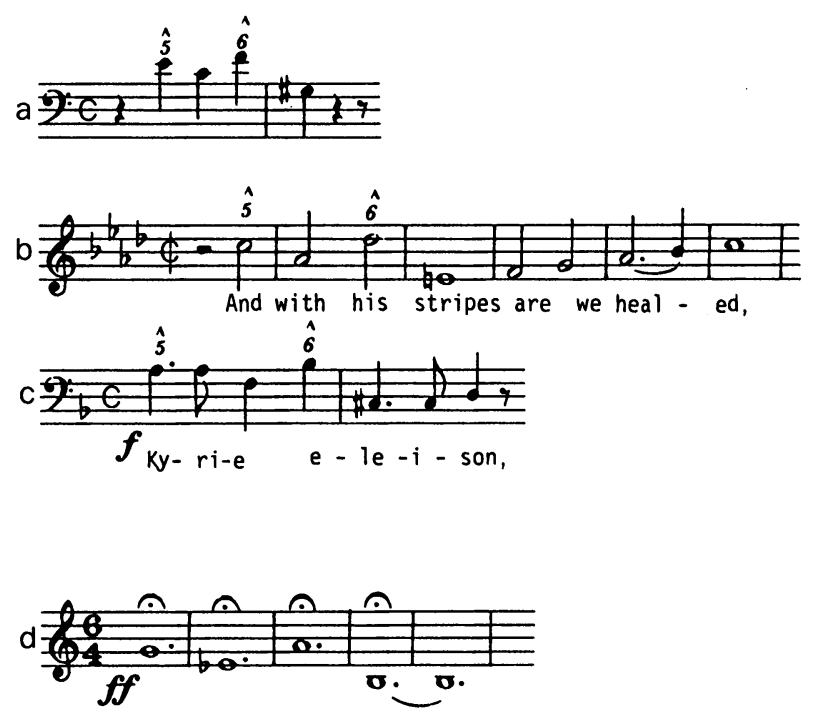

Fig. 18. (a) Bach, Fugue 20, Well-Tempered Clavier I, mm. 1-2; (b) Handel, "And with His Stripes," Messiah (Alla breve, moderato), mm. 1-6; (c) Mozart, Requiem (Kyrie), I (Allegro), mm. 49-50; (d) Holst, "Uranus, the Magician," The Planets, VI (Allegro), mm. $1-5$.

however, that the top-down invocation of schema here is highly dependent on conformant instantiation. For instance, the last melody in this group of examples (Figure 18d) seems to resemble all the other three cases in terms of melodic contour (down/up/down-a-skip), but its top-down style involves a very different sense of scale step. Hence, its first three tones do not activate in the same degree in the listener the expectation of a large, descending dramatic leap. ${ }^{21}$ In other words, in Figure 18d, the descending leap is, from the top-down perspective, slightly more surprising than the leaps of Figure $18 \mathrm{a}-\mathrm{c}$.

The phenomenon of suppression, whereby a relevant, top-down, learned formal schema inhibits the bottom-up implications of the various parameters belonging to it, can help explain strategies of musical development. In Figure 19, for instance, the aesthetic impact of the A in measure 6 results from the ascending line "breaking out" of the suppression caused by the mimicking repetition of the first phrase. That is, the listener initially expects the E-F\#-G in the first phrase to ascend to A, according to the

21. Schema invocation is like a conditioned response to an operant stimulus. And classical studies of conditioning involving combinational stimuli (as found in music) show that response and expectancy are highly dependent on perceptual conformance. This does not mean, of course, that we overlook the constructive nature of schema invocation. For schema mapping and expectation are not simply isomorphic, mirroring activities. Rather, once activated, they "spread" downward, from high-level abstractions to lower-level concretizations. 


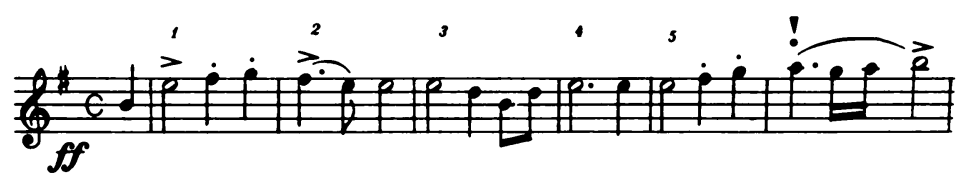

Fig. 19. Dvořák, Symphony No. 9, IV (Allegro con fuoco), mm. 34-39.

bottom-up system governing parametric implication. Subsequently, however, the listener stylistically "learns" here (and in three previous instances in this movement) that $\mathrm{E}-\mathrm{F} \#-\mathrm{G}$ is to reverse registral direction to $\mathrm{F \# ,} \mathrm{a}$ highly specific schematic instantiation that he or she maps onto the repeat at the beginning of the second phrase $(\mathrm{m} .5)$. Thus, the eventual realization of $\mathrm{A}$ emerges as a potent aesthetic event.

Replete with aesthetic affect, parametric realizations suddenly denying stylistic expectations exist everywhere in musical development, from simple melodic conflicts at local levels to complex parametric relations spanning whole works. ${ }^{22}$ In Figure 20a, for instance, the mild registral surprise (!) on $\mathrm{D} b$ in measure 3-denying the implied ascent of the C-Db-Eb-F in measures $1-2$ of the antecedent phrase-becomes stylistically normalized in the consequent phrase. The repetition thus suppresses the ascent and makes the change in registral direction between measures 6-7 expected (symbolized with the null, $\emptyset$ ). Thus, the start of the development section (Figure 20b) begins as if a full, mimicking repeat will occur, but then, suddenly, the learned suppression itself is denied with the realization of the originally implied ascent (continuing to $\mathrm{E} b$ and restoring the hegemony of the bottom-up system, as it were). The $A \#$ in measure 5 of Figure 20c follows the same aesthetic strategy, except that the denied suppression and sudden realization take place locally.

\section{The Origin of Formal Return}

Although there is much to say about return-perhaps the most important form of all-its aesthetic affect, like that of $A A B$ and $A B B$ forms, emerges from a unique interaction between both the bottom-up and topdown systems. For in terms of bottom-up strategies, a returning A forms a contiguously differentiated event $(\mathrm{C})$ in relation to a medial $\mathrm{B}$ and thus serves as a surprise. But in terms of top-down strategies, return functions as a discontiguous event of similarity (A) and therefore creates a surprise in this connection as well (see Figure 21). That is, return realizes one's

22. Indeed, there seem in melodic syntax to be two kinds of general aesthetic strategies - "immediate gratification" (such as we find in Romanticism) or "delayed gratification" (such as we find in Classicism). As music of the latter type requires both a higher degree of attention and a longer memory span, the cognitive "load" is probably greater. 


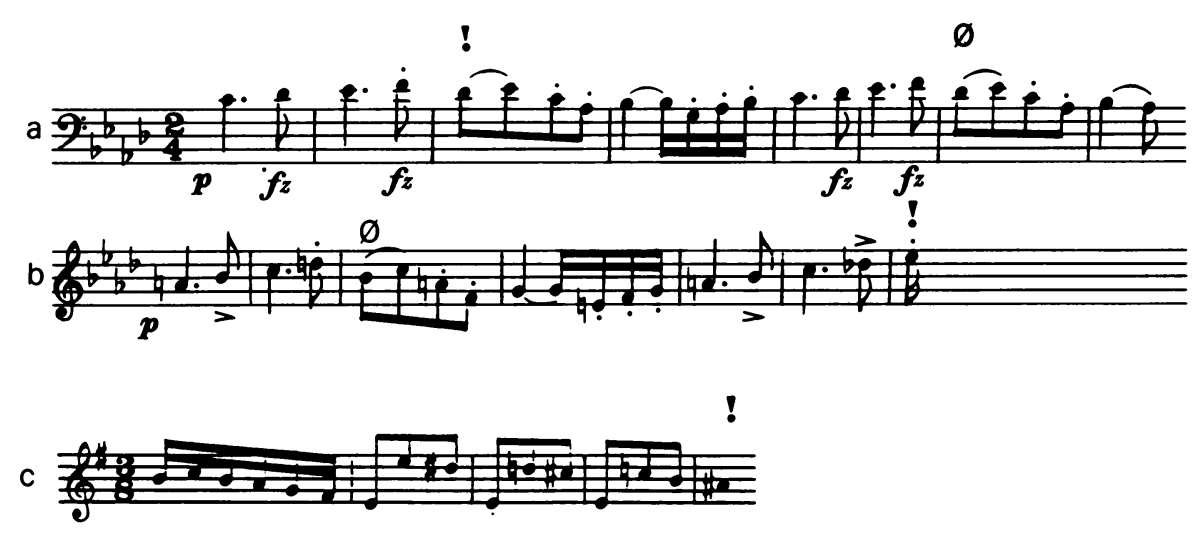

Fig. 20. (a) Beethoven, Sonata op. 31 no. 3, II, Scherzo (Allegretto vivace), mm. 1-8; (b) ibid., mm. 64-69; (c) Bach, Gigue, English Suite, BWV 810, mm. 1-4.

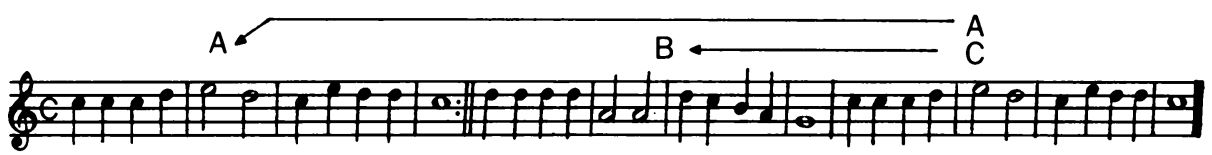

Fig. 21. Folksong, "Au clair de la lune."

implied perceptions concerning contiguous formal relations-where discontiguous similarity (the As of $\mathrm{A}+\mathrm{B}+\mathrm{A}$ ) displaces, according to the bottom-up system, the expected contiguous differentiation (the $\mathrm{BC}$ of $A+B+C)$. At the same time, return consummates one's learned expectations about discontiguous form-where contiguous differentiation (the $\mathrm{BA}$ of $\mathrm{A}+\mathrm{B}+\mathrm{A}$ ) substitutes for the contiguous similarity expected in top-down learning (the $B B$ of $A+B+B$ ).

Thus, the realization of formal return (ABA) aesthetically serves both $\mathrm{A}+\mathrm{B}$ implying $\mathrm{C}$ and $\mathrm{A}+\mathrm{B}+\mathrm{B}$ denying $\mathrm{C} .{ }^{23}$ And this argues why return is so satisfying: it, and only it, integrates the strategies and expectations generated within both the bottom-up and top-down systems. Perhaps this is why theorists like Koch (1781-1793/1983, pp. 84-86) seem to believe that formal return alone is a necessary and sufficient condition for musical unity.

Figure 22 illustrates how the two systems create the aesthetic effect of formal return. Of course, all the earlier remarks concerning the problem of theoretical falsifiability apply here as well.

23. Among the most interesting discrepancies within the bottom-up system are those in which parametric expectations conflict with formal expectations. Space, however, does not permit me to discuss this complication here. 


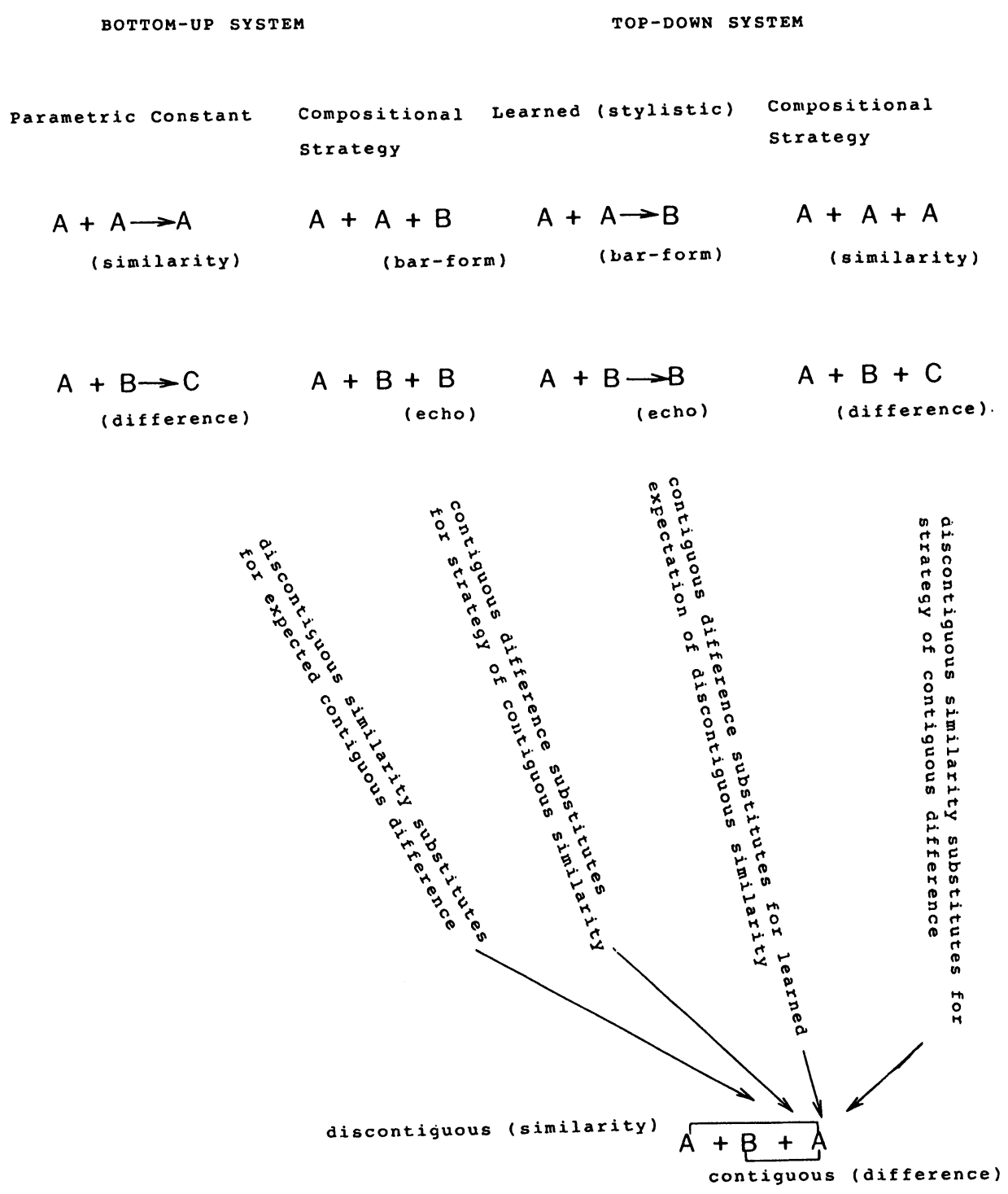

Fig. 22. 


\section{Conflict and Mismatch within the Top-Down System}

The top-down mapping of style on musical expectation and its influence on aesthetic effect come both from within and without a musical composition. Repetitions of events within a piece establish the perceptual relevance of intraopus style structures, whereas replications of events previously heard in other compositions cognitively produce impinging extraopus style structures. Although the humanistic term "style structure" and the cognitive words "musical schema" signify the same thing, the word "style" is not psychologically redundant. For it reminds us that listeners invoke schemata both "inside" and "outside" a piece, which is to say, call upon style from both the intraopus and extraopus perspective.

Three types of schema interruption and mismatch are possible. First, the norms of stylistic expectation within a specific piece may conflict (e.g., one form of intraopus repetition may vie with another). Second, such norms may conflict between two or more evoked styles (e.g., intraopus repetition may compete with extraopus replication). And third, mismatch may occur within the relevant extraopus style itself (e.g., one replicated continuation may conflict with another). For the listener, repetition within a piece (intraopus style) is cognitively concrete and thus of great perceptual immediacy, so implications generated within intraopus style usually take precedence over conflicting ones emanating from extraopus style. ${ }^{24}$

Figure 23 subtly illustrates the possibilities of schematic conflict within the top-down system. Melodically, concerning the intraopus style of measures 17-18, the repeated upbeat C-D to measure 19 seems to imply Eh. However, an intraopus stylistic mismatch is present because, harmonically, in measures $15-16$ and in two other previous places $(\mathrm{mm} .2-3$ and 9-10), an upbeat in this configuration implies the minor mode. Hence, the listener also envisions $\mathrm{E} b$ as a possible succession to C-D.

In addition, changing mode from major to parallel minor is not at all unusual in the Romantic period. Thus, here such change supports the expectation of an $\mathrm{Eb}$. Further, because in measures 18-19 the move from $\mathrm{C}$ major to $\mathrm{C}$ minor lies within the expected extraopus style, a conflicting mismatch between intraopus and extraopus style thus also exists.

24. But not always; for an instance, see the discussion of the second movement of Brahms's Double Concerto for Violin and Cello in Narmour (1990). One other point: the style structures (= schemata) that all experienced listeners share exist only at the abstract, generic level; yet, paradoxically, the style structures most relevant to any given listening experience-and thus the ones easiest to analyze and study empirically-take place on the foreground level. 

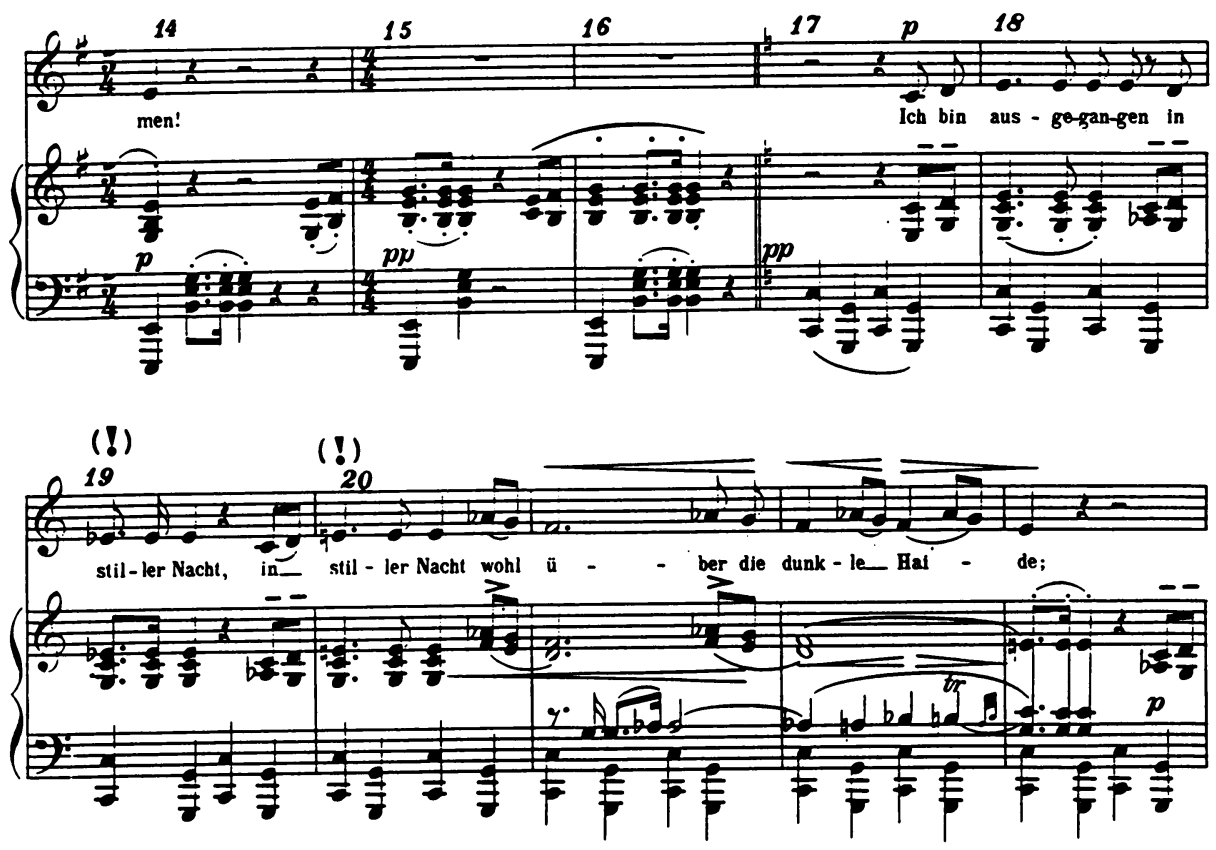

Fig. 23. Mahler, Songs of a Wayfarer, IV (Alla Marcia), mm. 14-23.

But that is not all. In late Romantic, early expressionistic music, of which this piece is an example, the simultaneous mixing of major and minor modes constitutes an extraopus stylistic norm as well. ${ }^{25}$ Hence, extraopus conflict between the mixing and changing of modes also obtains. Thus, in contrast to what was just argued concerning the expected extraopus style, harmonic mixing of mode here supports the expectation of $\mathrm{E} h$. In sum, the realization of $\mathrm{E} b$ in measure 19 is partly a surprise and a nonsurprise.

Significantly, also observe how Mahler skillfully manipulates the established stylistic complexity to yield yet another surprise in measure 20, where, on account of stylistic conformance to the preceding bar, the Eq that follows "should have been" $\mathrm{Eb}$.

\section{Conclusion}

Although parametrically the melodic motive of Figure 23 is simple (both C-D-E and C-D-Eb realize the implied registral direction and the intervallic motion generated within the bottom-up system), the complexity of both

25. A norm Mahler exploits in the remainder of this phrase. 
intraopus and extraopus stylistic mismatch in this example reminds us why art music will withstand considerable repetition before saturation and the reduction of aesthetic effect set in. For, as expectancy learning takes place (i.e., as one learns to predict the course of a musical pattern), logic says that one should cease to be surprised. Yet, the fact is, one can listen to the same piece over and over, with continuing aesthetic delight (Meyer, 1967, pp. 42-53).

The top-down system, with its vast potential for various complex possibilities of intraopus and extraopus stylistic mismatch and conflict, partly explains why musical repetition and replication remain aesthetically and perceptually viable. In short, the top-down system lends support to the many and various explanations arguing why the inherent complexity of "great" music offsets the conditioning of repeated listening experiences (Dowling \& Harwood, 1986; Jackendoff, 1987; Meyer, 1967; Moles, 1966).

The bottom-up system hypothesized by the implication-realization model offers further evidence why repetition does not completely diminish musical richness. For the learned, top-down system never completely penetrates or controls the bottom-up, "brute" system. That is, the bottom-up system always generates parametric and formal implications, regardless of the influence of the invoked stylistic schema. The listener thus continually experiences parametric denial and suppression of implication as an interruption and thus as an aesthetic surprise. Further, as frequency of repetition of a particular style structure or schema decreases, causing the listener's memory to undergo change and decay, the bottom-up system vis-à-vis perception and cognition reverts to its original strength before the learning of the style structure. This syntactically explains why all music lovers have had the reflexive experience of relistening to well-known, but temporarily discarded pieces with a renewed sense of aesthetic delight and emotional pleasure.

Yet, although many psychologists argue that sophisticated listeners desire complexity through schema discrepancy (e.g., Berlyne, 1971), other scholars and scientists have argued that naive listeners prefer simplicity through stylistic repetition and schematic replication (Smith \& Melara, in press; Coons \& Kraehenbuehl, 1958; Kraehenbuehl \& Coons, 1959).26 Thus, it remains to be seen how one might account for the evidence

26. Berlyne (1971) says that sophisticated humans desire arousal but notes that when interruption exceeds a certain limit, interest falls off. There is a stylistic explanation for this. For when denial of implication (=interruption) itself becomes an intraopus stylistic norm, a piece ceases to be interesting - as uninteresting as saturated repetition. Excessive denial of learned expectations is probably one of the problems that plagues contemporary music. 
concerning the naive listener's perception of syntactic meaning in music. ${ }^{27}$ That fact, however - that for some listeners $\mathrm{A}+\mathrm{A}+\mathrm{A}$ yields pleasure every time-requires more research and thus remains the subject of a future article. ${ }^{28}$

\section{References}

Angier, R. P. The conflict theory of emotion. American Journal of Psychology, 1927, 39, 390-401.

Berlyne, D. E. Aesthetics and psychobiology. New York: Appleton-Century-Crofts, 1971. Bharucha, J. Event hierarchies, tonal hierarchies, and assimilation, A reply to Deutsch and Dowling. Journal of Experimental Psychology, General, 1984, 113, 421-425.

Bregman, A. S. Auditory scene analysis: The perceptual organization of sound. Cambridge, MA: MIT Press, 1990.

Butler, D. Describing the perception of tonality in music: A critique of the tonal hierarchy theory and a proposal for a theory of intervallic rivalry. Music Perception, 1989, 6, 219-242.

Coons, E., \& Kraehenbuehl, D. Information as a measure of structure in music. Journal of Music Theory, 1958, 2, 127-161.

Deutsch, D. Grouping mechanisms in music. In D. Deutsch (Ed.), The psychology of music. New York: Academic Press, 1982.

Deutsch, D., \& Feroe, J. The internal representation of pitch sequences in tonal music. Psychological Review, 1981, 88, 503-522.

Dewey, J. The theory of emotion, I. Emotional attitudes. Psychological Review, 1894, 1, 553-569.

Dewey, J. The theory of emotion, II. The significance of emotions. Psychological Review, $1895,2,13-32$.

Dowling, W. J., \& Harwood, D. L. Music cognition. Orlando, FL: Academic Press, 1986.

Fodor, J. Modularity of mind. Cambridge, MA: MIT Press, 1983.

Francès, R. La perception de la music. Paris: Vrin, 1958.

Francès, R. The perception of music (W. Jay Dowling, Trans.). Hillsdale, NJ: Erlbaum, 1988.

Frijda, N. H. The emotions. Cambridge: Cambridge University Press, 1986.

Gjerdingen, R. O. A classic turn of phrase: Music and the psychology of convention. Philadelphia: University of Pennsylvania Press, 1988.

Hebb, D. O. On the nature of fear. Psychological Review, 1946, 53, 259-276.

Hebb, D. O. The organization of behavior. New York: Wiley, 1949.

Herbart, J. F. A text-book in psychology'(M. K. Smith, Trans.). New York: Appleton, 1891. (Original work published 1816).

Jackendoff, R. Consciousness and the computational mind. Cambridge, MA: MIT Press, 1987.

Jackendoff, R. Musical processing and musical affect. In M. R. Jones \& S. Holleran (Eds.), The cognitive basis of musical communication. Washington, DC: American Psychological Association (in press).

27. In a paper of limited scope, such as this, one can, of course, survey only a few topics. Concerning the aesthetic syntax of melody, I have thus necessarily had to omit discussing conflicts between implications occurring on different levels, conflicts between retrospective and prospective orientation, conflicts between competing perceptual analyses, conflicts between accelerated or delayed location of implied realizations, and so forth (the interested reader may wish to consult Narmour, 1991, and, in press).

28. A shortened and simplified version of this article was presented at the First International Conference on Music Perception and Cognition in Kyoto, Japan, October 1989. I thank Saul Sternberg and Thomas Christensen for their help with this article. 
Koch, H. C. Introductory essay on composition (Nancy K. Baker, Trans.). New Haven, CT: Yale University Press, 1983. (Original work published 1781-1793).

Kraehenbuehl, D., \& Coons, E. Information as a measure of the experience of music. Journal of Aesthetics, 1958, 17, 510-522.

Krumhansl, C. L. Perceptual structures for tonal music. Music Perception, 1983, 1, 28-62.

Krumhansl, C. L. Cognitive foundations of musical pitch. New York: Oxford University Press, 1990.

Krumhansl, C. L. Melodic structure: Theoretical and perceptual aspects. In Johan Sundberg (Ed.), Music, language, speech, and brain. London: Macmillan (in press).

Krumhansl, C. L., \& Schellenberg, E. G. An empirical test of the implication-realization model. Paper presented at the conference on Music and the Cognitive Sciences, Cambridge, England, September 17-21, 1990.

Lerdahl, F., \& Jackendoff, R. A generative theory of tonal music. Cambridge, MA: MIT Press, 1983.

Mandler, G. The interruption of behavior. In D. Levine (Ed.), Nebraska symposium on motivation. Lincoln, NB: University of Nebraska Press, 1964.

Mandler, G. Mind and body. New York: Norton, 1984.

Meyer, L. B. Emotion and meaning in music. Chicago: University of Chicago Press, 1956.

Meyer, L. B. Music, the arts, and ideas. Chicago: University of Chicago Press, 1967.

Meyer, L. B. Explaining music. Berkeley, CA: University of California Press, 1973.

Meyer, L. B. Grammatical simplicity and relational richness: The trio of Mozart's G minor symphony. Critical Inquiry, 1976, 2, 693-761.

Meyer, L. B. Process and morphology in Mozart's music. Journal of Musicology, 1982, 1, 67-94.

Meyer, L. B. Style and music: Theory, history, and ideology. Philadelphia: University of Pennsylvania Press, 1989.

Miller, G. A., Galanter, E. H., \& Pribram, K. H. Plans and the structure of behavior. New York: Holt, 1960.

Moles, A. Information theory and aesthetic perception (Joel E. Cohen, Trans.). Urbana, IL: University of Illinois Press, 1966.

Narmour, E. Beyond Schenkerism: The need for alternatives in music analysis. Chicago: University of Chicago Press, 1977.

Narmour, E. Some major theoretical problems concerning the concept of hierarchy in the analysis of tonal music. Music Perception, 1983, 1, 129-199.

Narmour, E. Toward an analytical symbology: The melodic, harmonic and durational functions of implication and realization. In M. Baroni \& L. Callegari (Eds.), Musical grammars and computer analysis. Florence: Olschki, 1984.

Narmour, E. The 'genetic code' of melody: Cognitive structures generated by the implication-realization model. In S. McAdams \& I. Deliège (Eds.), Music and the cognitive sciences. London: Harwood, 1989a.

Narmour, E. L'implication et la réalisation mélodique dans ' $L a$ terrasse des audiences du clair de lune' de Debussy. Analyse musicale, 1989b, 16, 44-53.

Narmour, E. The analysis and cognition of basic melodic structures: The implicationrealization model. Chicago: University of Chicago Press, 1990.

Narmour, E. The analysis and cognition of melodic complexity: The implicationrealization model. Chicago: University of Chicago Press, 1992.

Narmour, E. The influence of embodied registral motion on the perception of melodic implication at higher levels. In M. R. Jones \& S. Holleran (Eds.), The cognitive basis of musical communiration. Washington, DC: American Psychological Association (in press).

Navon, $D$. Forest before trees: The precedence of global features in identification. Cognitive Psychology, 1977, 9, 353-383.

Ortony, A., Clore, G., \& Collins, A. The cognitive structure of emotions. Cambridge: Cambridge University Press, 1988.

Paulhan, F. Les phénomènes affectifs et les lois de leur apparition. Paris: Alcan, 1887.

Paulhan, F. The laws of feeling (C. K. Ogden, Trans.). New York: Harcourt, Brace, 1930. 
Pomerantz, J. R. Perceptual organization in information processing. In M. Kubovy \& J. R. Pomerantz (Eds.), Perceptual organization. Hillsdale, NJ: Erlbaum, 1981.

Reisenzein, R. The Schachter theory of emotion: Two decades later. Psychological Bulletin, 1983, 94, 239-264.

Rosner, B. S. Music perception, music theory, and psychology. In E. Narmour \& R. Solie (Eds.), Explorations in music, the arts, and ideas. Stuyvesant, NY: Pendragon, 1988.

Rosner, B. S., \& Meyer, L. B. Melodic processes and the perception of music. In D. Deutsch (Ed.), The psychology of music. New York: Academic Press, 1982.

Rosner, B. S., \& Meyer, L. B. The perceptual roles of melodic process, contour, and form. Music Perception, 1986, 4, 1-39.

Rumelhart, D. E., \& Ortony, A. The representation of knowledge in memory. In R. C. Anderson, R. J. Spiro, \& W. E. Montague (Eds.), Schooling and the acquisition of knowledge. Hillsdale, NJ: Erlbaum, 1977.

Schachter, S., \& Singer, J. E. Cognitive, social, and physiological determinants of emotional state. Psychological Review, 1962, 69, 379-399.

Schenker, H. Der Freie Satz. Vienna: Universal, 1956.

Serafine, M. L. Music as cognition. New York: Columbia University Press, 1988.

Smith, J. D., \& Melara, R. J. Aesthetic preference and syntactic prototypicality in music. Cognition (in press).

Toch, E. The shaping forces in music. New York: Dover, 1977.

Weimer, E. Opera seria and the evolution of classical style 1755-1772. Ann Arbor, MI: UMI Press, 1984. 